\title{
Screening of Shoot and Fruit Borer (Leucinodes orbonalis Guenee.), for Resistance in Brinjal (Solanum melongena L.) Germplasm Lines
}

\author{
M. Netam*, R. Lakra, V.K. Koshta, D. Sharma and S. Deole \\ Department of Entomology, Indira Gandhi Krishi Vishwavidyalaya, Raipur (C.G), India \\ *Corresponding author
}

A B S T R A C T

Keywords

Brinjal,

Screening,

Germplasm lines,

Shoot and Fruit

borer, Resistance

Article Info

Accepted:

28 January 2018

Available Online:

10 February 2018

Response of different brinjal genotypes against brinjal shoot and fruit borer (Leucinodes orbonalis Guenee.) was evaluated at horticulture research field of Indira Gandhi Krishi Vishwavidyalaya, Raipur (C.G) during kharif, 2015-2016. 106 brinjal germplasm lines were evaluated for resistance to shoot and fruit borer. Minimum mean infestation in fruits was found in genotype IGB-92 (20.83\%) while maximum mean infestation in fruits was recorded in IGB-89 (79.30\%). Among 106 germplasm lines of brinjal, two of them IGB-92 and IGB-93 were found moderately tolerant, 24 were found susceptible, rest 80 germplasm lines were highly susceptible and none of the brinjal were found resistance to shoot and fruit borer.

\section{Introduction}

Eggplant (Solanum melongena) is one of the most important vegetables in South and South-East Asia. It is grown on over 678,000 ha, which is about $37 \%$ of the world eggplant area, with a production of 10.50 million ton (FAO, 2007). It is cultivated allyear round in different parts of India and serves as the main source of income for many rural farmers and households. Production is however constrained by a wide range of pests and diseases, reducing total production as well as production quality.

A great diversity of species of insects from different Orders and Families have been recorded on the brinjal of which very few are of economic importance.

The brinjal fruit and shoot borer (BFSB) Leucinodes orbonalis (Lepidoptera: Pyrallidae) is one of the most important destructive insect pest of this vegetable crop.

Leucinodes orbonalis Guenee was described by Guenee in 1854 . The preferred scientific name of the eggplant fruit and shoot borer is Leucinodes orbonalis Guenee, 1854.

The taxonomic position according to $\mathrm{CABI}$ (2007) is given as: 
Phylum: Arthropoda

Class: Insecta

Order: Lepidoptera

Family: Crambidae (Syn: Pyralidae)

Genus: Leucinodes

Species: orbonalis

Scientific name: Leucinodes orbonalis

Guenee

Host range of $L$. orbonalis Guenee is practically monophagous, feeding principally on eggplant; however, other plants belonging to family Solanaceae are reported to be hosts of this pest. It is the most important and the first ranked pest of India, Pakistan, Srilanka, Nepal, Bangladesh, Thailand, Philippines, Cambodia, Laos and Vietnam (AVRDC, 1994). Its distribution is mostly higher in those areas having hot and humid climate (Srinivasan, 2009).

It could cause yield reduction as high as 70\% (Islam and Karim, 1991; Dhandapani et $a l .$, 2003). The losses caused by pest vary from season to season because moderate temperature and high humidity favour the population build-up of brinjal shoot and fruit borer (Shukla and Khatri, 2010), (Bhushan et al., 2011). Like other members of the order Lepidoptera, L. orbonalis goes through four growth stages: egg, larva, pupa and adult. The larval period is the longest, followed by pupal and incubation period. Oviposition takes place during the night and eggs are laid singly on the lower surface of the young leaves, green stems, flower buds, or calyces of the fruits and number of eggs laid by a female varies from 80 to 253 (Taley et al.,1984; Alpuerto, 1994). The eggs are laid in the early hours of the morning singly or in the batches on the ventral surface of the leaves (CABI, 2007). Eggs are flattened, elliptical with $0.5 \mathrm{~mm}$ in diameter and colour is creamy-white but change to red before hatching (Alam et al., 2006). The egg takes incubation period of 3 5 days in summer and 7-8 days in winter and hatch into dark white larvae. The larval period lasts 12 - 15 days during summer and 14 - 22 days during winter season (Rahman, 2006). Larvae pass through at least five instars (Atwal, 1976) and there are reports of the existence of six larval instars (Baang and Corey, 1991; FAO, 2003).

At vegetative phase, the newly hatched larvae borer into petioles, midrib of large leaves and young tender shoots. They feed on the internal tissue causing the shoot drooped down and withered at the reproductive phase the larvae prefers to bore into flower buds and also enter into the infested fruits through the calyx. Observing the boring holes, the infested fruits can easily be identified. Besides, the dark colour excreta can easily be seen to the hole of infested fruits Larvae of this insect bore inside plant shoots and fruits, adversely affecting plant growth, yield and fruit quality, and thus making it unfit for human consumption.

Hence, to produce damage-free marketable fruits and to avoid production loss, the farmers in the region rely exclusively on the application of chemical insecticides to combat EFSB which has resulted in a tremendous misuse of pesticides. Indiscriminate use of insecticides to the control of the EFSB and other vegetables, result in soil, water and environmental pollution as well as bioaccumulation and bio-magnification of toxic residues and causes disturbance in ecological balance. So there is a need for an expedient to seek for safe and eco-friendly pest control measures. The most important and effective way to manage an insect pest is the use of resistant cultivars and it can be easily adopted with reduced cost of production. The use of 
resistant varieties is regarded as the farmer's first line of defense against pests and one of the safest and most compatible approach with other control strategies (Lit, 2009).Therefore the application of Integrated pest management (IPM) is desirable and sustainable in managing these pests because it combines biological, cultural, physical, and chemical tools in a way that minimizes economic, health and environmental risks (Rechcigl and Rechcigl, 2000). Hence the study was conducted in field condition, with the objective to determine the response of brinjal germplasm lines against shoot and fruit borer.

\section{Materials and Methods}

An experiment was conducted at horticulture research field of Indira Gandhi Krishi Vishwavidyalaya, Raipur (C.G) during kharif, 2015-2016. 106 brinjal germplasm lines were screened against brinjal shoot and fruit borer. Each genotype was sown in a five row of 2.5 meters length, spacing $60 \mathrm{~cm}$ row to row with $50 \mathrm{~cm}$ from plant to plant. For raising a healthy crop, except plant protection measures all the recommended package of practices notified by the Indira Gandhi Krishi Vishwavidyalaya was followed. Five plants were tagged at random and observed for the incidence of shoot and fruit borer in each brinjal genotype at seven days interval from transplanting to harvest.

From randomly selected five plants, in each genotype, infested and healthy fruits were counted and weighed in all pickings and thereafter fruit-infestation per cent was calculated.

On the basis of mean fruit infestation percentage all genotypes were categorized in different categories grade formula given by subbaratnam and bhutani (1981). Grade- 1, tolerant (1 to $15 \%$ fruit infestation), grade2 , moderately tolerant (16 to $25 \%$ fruit infestation) grade-3, susceptible (26 to $40 \%$ fruit infestation) and grade- 4 highly susceptible (above 40\%).

\section{Result and Discussion}

Infestation percent of shoot and fruit borer was recorded in brinjal germplasm, ranged from 20.83 to 79.30. Minimum mean infestation in fruits was found in genotype IGB-92 (20.83\%) while maximum mean infestation in fruits was recorded in IGB-89 (79.30\%). Mean percent infestation of shoot and fruit borer in fruits has been presented in Table 2.

Table. 1 shows the per cent level of infestation by shoot and fruit borer in brinjal germplasm, categorization formula given by subbaratnam and bhutani (1981).

\begin{tabular}{|l|l|l|}
\hline Level of infestation $(\%)$ & Categories & Grade \\
\hline $\mathbf{1 - 1 5}$ & Tolerant & T \\
\hline $\mathbf{1 6 - 2 5}$ & Moderately tolerant & MT \\
\hline $\mathbf{2 6 - 4 0}$ & Susceptible & S \\
\hline Above 40 & Highly susceptible & HS \\
\hline
\end{tabular}


Table. 2 shows the mean per cent infestation of fruit in different brinjal germplasm

\begin{tabular}{|c|c|c|c|c|c|c|c|}
\hline Genotype & \%infestation & genotype & \%infestation & genotype & \%infestation & genotype & \%infestation \\
\hline IGB-1 & 59.38 & IGB-30 & 65.08 & IGB-59 & 58.89 & IGB-88 & 71.05 \\
\hline IGB-2 & 51.13 & IGB-31 & 33.65 & IGB-60 & 50.76 & IGB-89 & 79.30 \\
\hline IGB-3 & 61.01 & IGB-32 & 45.71 & IGB-61 & 35.94 & IGB-90 & 40.76 \\
\hline IGB-4 & 61.46 & IGB-33 & 52.54 & IGB-62 & 43.32 & IGB-91 & 28.20 \\
\hline IGB-5 & 62.36 & IGB-34 & 32.74 & IGB-63 & 57.44 & IGB-92 & 20.83 \\
\hline IGB-6 & 58.72 & IGB-35 & 36.68 & IGB-64 & 45.03 & IGB-93 & 22.21 \\
\hline IGB-7 & 54.55 & IGB-36 & 48.53 & IGB-65 & 39.71 & IGB-94 & 31.35 \\
\hline IGB-8 & 59.64 & IGB-37 & 68.59 & IGB-66 & 39.99 & IGB-95 & 43.16 \\
\hline IGB-9 & 56.42 & IGB-38 & 60.55 & IGB-67 & 62.08 & IGB-96 & 45.53 \\
\hline IGB-10 & 60.05 & IGB-39 & 54.59 & IGB-68 & 74.36 & IGB-97 & 69.07 \\
\hline IGB-11 & 55.08 & IGB-40 & 60.32 & IGB-69 & 48.68 & IGB-98 & 60.77 \\
\hline IGB-12 & 59.77 & IGB-41 & 51.58 & IGB-70 & 35.30 & IGB-99 & 27.60 \\
\hline IGB-13 & 61.80 & IGB-42 & 45.88 & IGB-71 & 29.25 & IGB-100 & 50.71 \\
\hline IGB-14 & 68.47 & IGB-43 & 44.46 & IGB-72 & 38.63 & IGB-101 & 54.30 \\
\hline IGB-15 & 67.34 & IGB-44 & 44.13 & IGB-73 & 38.57 & IGB-102 & 46.99 \\
\hline IGB-16 & 52.65 & IGB-45 & 58.35 & IGB-74 & 47.46 & IGB-103 & 43.44 \\
\hline IGB-17 & 52.57 & IGB-46 & 29.64 & IGB-75 & 40.41 & IGB-104 & 27.18 \\
\hline IGB-18 & 35.95 & IGB-47 & 70.67 & IGB-76 & 43.51 & IGB-105 & 46.24 \\
\hline IGB-19 & 67.18 & IGB-48 & 61.82 & IGB-77 & 50.49 & IGB-106 & 34.33 \\
\hline IGB-20 & 57.92 & IGB-49 & 47.61 & IGB-78 & 42.14 & & \\
\hline IGB-21 & 59.68 & IGB-50 & 59.27 & IGB-79 & 66.31 & & \\
\hline IGB-22 & 64.12 & IGB-51 & 61.86 & IGB-80 & 58.87 & & \\
\hline IGB-23 & 30.03 & IGB-52 & 48.30 & IGB-81 & 62.02 & & \\
\hline IGB-24 & 39.77 & IGB-53 & 37.46 & IGB-82 & 49.46 & & \\
\hline IGB-25 & 34.69 & IGB-54 & 50.01 & IGB-83 & 73.51 & & \\
\hline IGB-26 & 51.56 & IGB-55 & 55.99 & IGB-84 & 61.46 & & \\
\hline IGB-27 & 36.63 & IGB-56 & 67.84 & IGB-85 & 57.08 & & \\
\hline IGB-28 & 39.32 & IGB-57 & 64.53 & IGB-86 & 58.68 & & \\
\hline IGB-29 & 73.67 & IGB-58 & 59.85 & IGB-87 & 56.99 & & \\
\hline
\end{tabular}




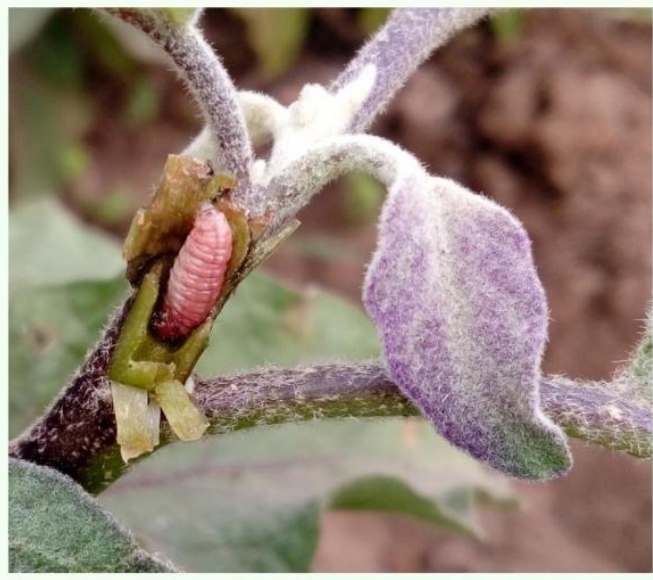

Shoot and fruit borer (Leucinodes orbonalis)

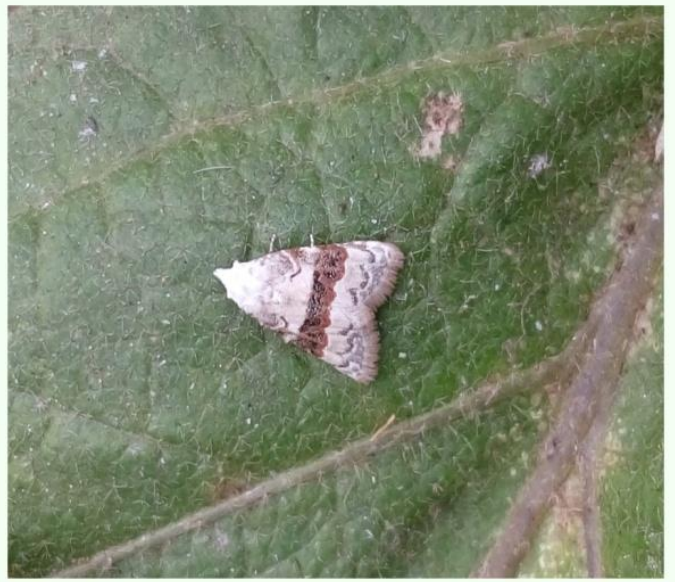

Adult shoot and fruit borer

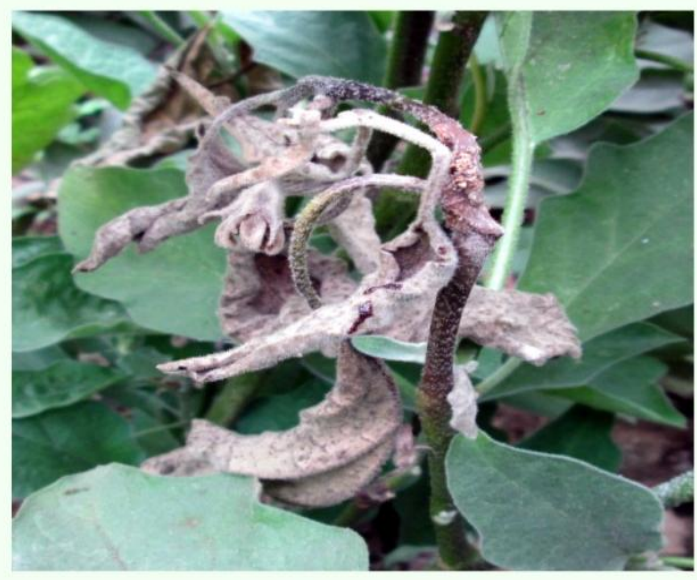

Infested Shoot

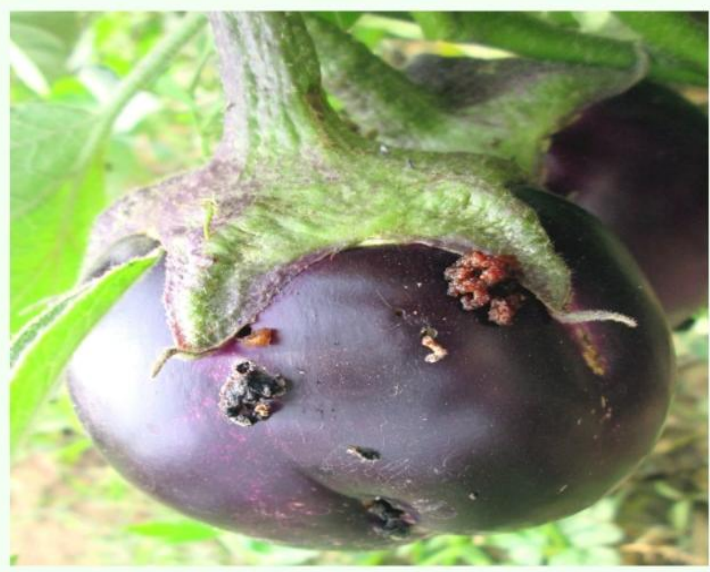

Infested Fruit

Fig: : Shoot and Fruit infestation by leucinodes orbonalis 
Among 106 brinjal germplasm none of the germplasm was tolerant to Leucinodes orbonalis. Sridhar et al. (2001) reported fifty-four brinjal (aubergine) germplasm, including 5 wild species and some F1 crosses and Mandal et al. (2005) reported thirty-one brinjal (aubergine) cultivar, that none of the cultivated/wild species of brinjal was found resistant to L. orbonalis. Another screening program involved only 20 accessions, and none of them exhibited significant levels of resistance (Hossainet al., 2002).

Two germplasm IGB-92 and IGB-93 were moderately tolerant with 20.83 and 22.21 per cent fruit infestation whereas they showed 2.73 and 2.88 per cent shoot infestation. Tolerant entries of brinjal are highly useful in IPM to augment the natural enemies rather than resistant and fairly resistant entries. The tolerance nature of above entries of brinjal might be attributed by hardness of the fruit skin and flesh (Krishnaiah and Vijay, 1975) and hard to semi-hard shoot and medium to dense pubescence (Raut and Sonone, 1980).

Next 24 germplasm were susceptible with the fruit infestation per cent range from 27.18 (IGB- 104) to 40.76 (IGB-90), whereas they showed 2.26 and 2.67 per cent shoot infestation. Similarly, Ashoke and Abhishek (2002) while evaluating 12 aubergine cultivars in field conditions reported 33.65- 53.02\% fruit infestation of L. orbonalis larvae. Comparable range of fruit infestation was 20.23 to $45.61 \%$ reported by Jat et al., (2003).

And rest of the 80 germplasm lines was highly susceptible to Leucinodes orbonalis (shoot and fruit borer) with the fruit infestation per cent range from 41.99 (IGB66) to 79.30 (IGB-89), recording 2.18 and 2.84 per cent shoot infestation.
Khan and Singh (2014) reported, among 192 genotypes of brinjal tested, two of them EC305163 and IC090132 was found immune to shoot and fruit borer, three genotype namely IC545256, IC433625 and IC264470 found resistance, 21 fairly resistance, 38 tolerant, 52 susceptible and rest 76 genotypes were found highly susceptible to brinjal shoot and fruit borer.

\section{References}

Alam SN, Hossain MI, Rouf FMA, Jhala RC, Patel MG, Rath LK, Sengupta A, Baral K, Shylesha AN, Satpathy S, Shivalingaswamy TM, Cork A and Talekar NS (2006) Implementation and promotion of an IPM strategy for control of eggplant fruit and shoot borer in South Asia. Technical Bulletin No. 36. AVRDC publication number 06-672. AVRDC The World Vegetable Center, Shanhua, Taiwan. $74 \mathrm{p}$.

Alpuerto AB (1994) Ecological studies and management of brinjal fruit and shoot borer, Leucinodes orbonalis Guenee. Indian Journal of Agricultural Sciences 52(6): 391-395.

Ashoke, K. and Abhishek, S. 2002. Varietal preference of fruit and shoot borer, Leucinodes orbonalis Guen. on brinjal. Insect Environ.8(1): 44.

Atwal AS (1976) Agricultural pests of India and Southeast Asia. Kalyani Publishers. New Delhi, India. 529 p.

AVRDC (1994) Eggplant entomology. Control of eggplant fruit and shoot borer. Progress Report. Asian Vegetable Research and Development Center, (AVRDC), Shanhua, Taiwan. $88 \mathrm{p}$

Baang LA and Corey FM (1991) Life history of an eggplant fruit and shoot borer, Leucinodes orbonalis (Guenee) (Lepidoptera: Pyralidae). Chiang Mai University Journal of Science 4(1): 45-61 (Abs.).

Bhushan, S., Chaurasia, H. K. and Shanker, R. 2011. Efficacy and economics of pest management modules against brinjal shoot and fruit borer (Leucinodes 
orbonalis). The Bioscan. 6(4): 639-642.

CABI (2007) Crop protection compendium. CAB International (Available at: http://www.cabicompendium.org/cpc )

Dhandapani, N., Shelkar, U. R. and Murugan, M. 2003. Bio-intensive pest management in major vegetable crops: An Indian perspective. Journal of Food, Agriculture and Environment, 1(2): 330-339.

FAO (2003) Eggplant integrated pest management an ecological guide. FAO inter-country programme for integrated pest management in vegetables in South and Southeast Asia. Bangkok, Thailand. $177 \mathrm{p}$.

FAO. 2007. FAOSTAT data 2005. http://www.fao.org (accessed on 28 August 2007)

Hossain, M. M., Shahjahan, M., Abdus Salam, M. and Begum, M. A. 2002. Screening of some brinjal varieties and lines against brinjal shoot and fruit borer, Leucinodes orbonalis Guenee. Pakistan Journal of Biological Sciences, 5(10): 1032-1040

Islam, M. N. and Karim, M. A. 1991. Management of the brinjal shoot and fruit borer, Leucinodes orbonalis Guen, (Lepidoptera: Pyralidae) in field. In: Annual Research Report 1990-91. Entomology Division, Bangladesh Agric. Res. Inst. Joydebpur, Gazipur, $44-46$ PP.

Khan, R. and Singh, Y.V.2014. Screening for shoot and fruit borer (Leucinodes orbonalis Guenee.) resistance in brinjal (Solanum melongena L.) genotypes. The Ecoscan. pp: 41-45.

Krishnaiah, K. and Vijay, O. P. 1975. Evaluation of brinjal varieties for resistance to shoot and fruit borer, Leucinodes orbonalis Guen. Indian J. of Hort. 32(1-2): 84-86.

Lit MC (2009) Combined resistance of eggplant, Solanum melongena L., to leafhopper, Amrasca biguttula (Ishida) and the eggplant borer, Leucinodes orbonalis Guenee. M. Sc. Thesis, University of Los Baños, Laguna, Philippines. 191 p.

Rahman MM (2006) Vegetable IPM in Bangladesh. Department of Entomology. Bangabandhu Sheikh Mujibur Rahman Agricultural University Gazipur, Bangladesh (Availableat: http://ipmworld.umn.edu/chapters/rahman .htm )

Raut, U. M. and Sonone, H. N. 1980. Tolerance in brinjal varieties to shoot and fruit borer (Leucinodes orbonalis Guen.). Vegetable Science. 7(1): 74-78.

Rechcigl A and R. Rechcigl (eds). 2000. Insect Pest Management: Techniques for Environmental Protection. CRC Press. Florida. 391pp.

Shukla, A. and Khatri S. N. 2010. Incidence and abundance of brinjal shoot and fruit borer Leucinodes orbonalis Guenee. The Bioscan. 5(2): 305-308.

Srinivasan R (2009) Insect and mite pests on eggplant: a field guide for identification and management. AVRDC Publication No. 09-729. AVRDC - The World Vegetable Center, Shanhua, Taiwan. 64 p.

Taley YM, Nighut US and Rajurkar BS (1984) Bionomics of brinjal fruit and shoot borer, (Leucinodes orbonalis Guenee). Punjabrao Krishi Vidyapeeth Research Journal 8(1): 29-39.

\section{How to cite this article:}

Netam, M., R. Lakra, V.K. Koshta, D. Sharma and S. Deole. 2018. Screening of Shoot and Fruit Borer (Leucinodes orbonalis Guenee.), for Resistance in Brinjal (Solanum melongena L.) Germplasm Lines. Int.J.Curr.Microbiol.App.Sci. 7(02): 3700-3706. doi: https://doi.org/10.20546/ijcmas.2018.702.439 